
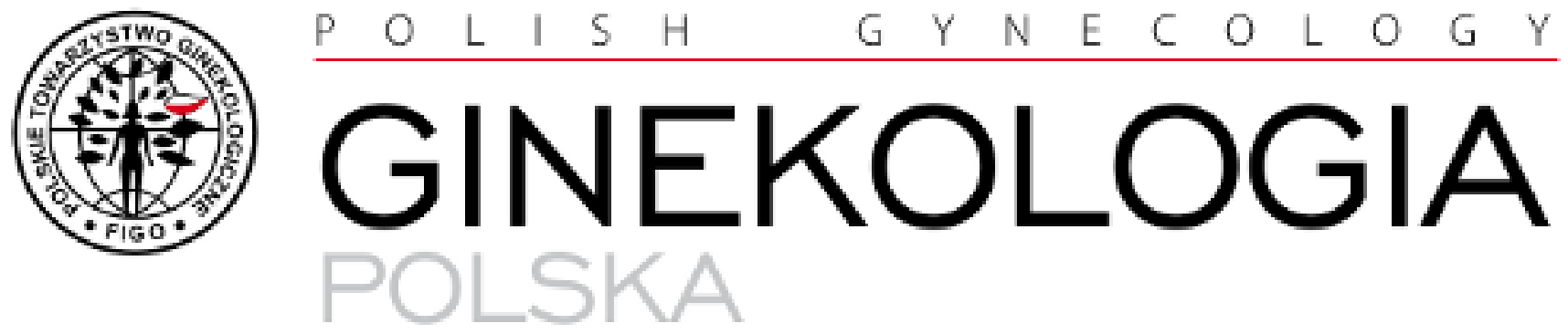

ORGAN POLSKIEGO TOWAAZYSTWA GINE KOLOGICZNEGO

THE OFFICIAL JOURNAL OF THE POLISH GYNECOLOGICAL SOCIETY

ISSN: 0017-0011

e-ISSN: $2543-6767$

\title{
Clinical significance of S100B protein in pregnant woman with early- onset severe preeclampsia
}

Authors: Jinxia Wu, Xiaoqi Sheng, Shaoming Zhou, Chaoying Fang, Yulin Song, Hua Wang, Zhengjun Jia, Xiaozhou Jia, Yiping You

DOI: $10.5603 / G P . a 2021.0126$

Article type: Research paper

Submitted: $2020-03-30$

Accepted: $2021-04-05$

Published online: 2021-05-21

This article has been peer reviewed and published immediately upon acceptance.

It is an open access article, which means that it can be downloaded, printed, and distributed freely, provided the work is properly cited.

Articles in "Ginekologia Polska" are listed in PubMed. 
ORIGINAL PAPER / OBSTETRICS

\title{
Clinical significance of S100B protein in pregnant woman with early- onset severe preeclampsia
}

Jinxia $\mathrm{Wu}^{1}$, Xiaoqi Sheng ${ }^{2}$, Shaoming Zhou ${ }^{2}$, Chaoying Fang ${ }^{2}$, Yulin Song ${ }^{1}$, Hua Wang ${ }^{3}$, Zhengjun $\mathrm{Jia}^{3}$, Xiaozhou Jia ${ }^{1}$, Yiping You ${ }^{1}$

${ }^{1}$ Department of Obstetrics, Maternal and child health hospital of Hunan Province Changsha, Hunan, China

${ }^{2}$ Department of Hospital office, Maternal and child health hospital of Hunan Province Changsha, Hunan, China

${ }^{3}$ Department of Genetics, Maternal and child health hospital of Hunan Province Changsha, Hunan, China

\section{Corresponding author:}

Yiping You

YiPing You, Professor, Department of Obstetrics, Maternal and child health hospital of Hunan Province, 53 Xiangchun Road, Changsha, Hunan 410001, PR China

phone: +86-0731-89773166, fax: +86-0731-84332122

e-mail: yipingy2020@126.com

\section{Running title: S100B in pregnancy with preeclampsia}

\begin{abstract}
Objectives: Preeclampsia is one of the most feared complications of pregnancy, which can progress rapidly to serious complications such as death of both mother and fetus. To present, the leading cause of preeclampsia is still debated. The purpose of this article was to explore the
\end{abstract}


clinical significance of $\mathrm{S} 100 \mathrm{~B}$ protein, a kind of $\mathrm{Ca}^{2+}$-sensor protein, in the early-onset severe preeclampsia.

Material and methods: Nine pregnant women with early-onset severe preeclampsia (the study group) and 13 healthy pregnant women (the control group) were included in this study. The level of S100B in the amniotic fluid, maternal blood, and umbilical cord blood were detected by enzyme-linked immunosorbent assay (ELISA) and surface plasmon resonance imaging (SPRi) methods. Diagnostic values of S100B for early-onset severe preeclampsia were assessed by Receiver Operating Characteristic (ROC) curve analysis.

Results: The levels of S100B in maternal blood and amniotic fluid in the study group were higher than those in the control group $(\mathrm{p}<0.05)$. ROC curve analysis showed that S100B detected by SPRi method (SPRi-S100B) showed a cut-off level of $181 \mathrm{ng} / \mathrm{mL}$ with sensitivity of $100 \%$, a specificity of $84.6 \%$, and a Youden index of 0.846 in the maternal blood, which had better clinical significance and diagnostic value (at than that detected by ELISA (ELISA-S100B).

Conclusions: The levels of S100B detected by SPRi in maternal blood can indicate early-onset severe preeclampsia and perinatal brain injury.

Key words: S100B; early-onset severe preeclampsia; enzyme-linked immunosorbent assay; surface plasmon resonance imaging

\section{INTRODUCTION}

Preeclampsia is a severe condition with high blood pressure and increased protein in the urine in pregnant women. It commonly occurs after gestational week 20 and can be divided into early-onset (<34 weeks) and late-onset (> 34 weeks) preeclampsia. It is believed that early-onset and late-onset preeclampsia have different aetiologies and pathogenesis, although both can cause high morbidity and mortality for pregnant women and fetuses $[1,2]$. Prompt recognition and diagnosis of preeclampsia and perinatal brain injury (PBI) are essential to save lives and improve outcomes [3]. However, most clinical studies have focused on late-onset preeclampsia, and relatively few studies investigated early-onset preeclampsia.

Researchers have searched for various markers of brain injury to diagnose preeclampsia and PBI early, as preeclampsia can cause PBI in the fetus. Perinatal brain injury (PBI) is the main cause of perinatal death and long-term disability. It is reported that $8 \%$ of full-term infants suffer from cerebral palsy due to asphyxia at birth, and $40 \%$ of preterm infants die of perinatal death 
due to neurological defects [4]. Pierrat et al. [5], (2005) found that prenatal-perinatal asphyxia accounts for $10 \%$ and postpartum asphyxia accounts for $2 \%$ in newborn encephalopathy. At present, scholars lack a unified understanding of the diagnosis of this condition. Current understanding of PBI by obstetricians is that preventive measures must be taken in a timely manner; however, this remains controversial. Therefore, measures must be taken to diagnose PBI in a timely and accurate manner.

Several studies have reported that the S100B protein expression is elevated in pregnant women with preeclampsia, indicating the involvement of S100B protein in preeclampsia [6]. The S100B protein synthesized and secreted by brain neuroglia and Schwann cells is a member of the S100 protein family (calcium-regulation protein) [7]. It acts as both an intracellular regulator and a secreted signaling molecule and plays important roles in many cellular processes such as cell proliferation, differentiation, migration, and apoptosis [8]. Alterations in the level of expression of S100B can lead to four different categories of diseases including the heart disease, central nervous system disease, inflammatory disorders and cancer [9]. It was found that the effects and physiological functions of S100B are concentration dependent. A low concentration (nanomolar level) of S100B can nourish and support the neuroglia and neurons, which facilitates nerve growth and injury repair. A high concentration (micromolar level) of S100B can have toxic effects on nerves to induce neuron degeneration apoptosis and death [10]. S100B is sensitive enough to detect and evaluate different types of intracranial trauma, such as traumatic subarachnoid hemorrhages and epidural hematomas, depending on the receptor for advanced glycation end-products (RAGE) which is up-regulated by S100B levels and may lead to proinflammatory gene activation [11]. Some researchers have described S100B as "the C-reactive protein (CRP) of the brain." [12] and suggested its use in monitoring fetal distress and other highrisk fetuses [13]. In 2012, Cai et al. [14], reported that the S100B expression in women with early-onset preeclampsia was significantly higher than that in the control group and in late-onset preeclampsia group, indicating that $\mathrm{S} 100 \mathrm{~B}$ may be a risk factor in early-onset preeclampsia. Serum S100B levels may also be suitable markers of severe preeclampsia given the severity of hypoperfusion both in the placenta and brain [15]. In another previous study, S100B levels were found to be much higher in women with preeclampsia than that in control subjects, and high $\mathrm{S} 100 \mathrm{~B}$ is significantly associated with visual impairment in the preeclampsia group [6] S100B protein may help obstetrician screen for PBI, monitor the progression of the disease, identify the 
timing of the injury, and predict the time of birth [16]. The level of S100B may be an ideal indicator for the diagnosis in preeclampsia and PBI, however, it is difficult to detect S100B at the mRNA level in clinical laboratories.

In our study, we examined the S100B expression levels in the maternal blood, amniotic fluid, and umbilical cord blood in pregnant women with preeclampsia using ELISA and SPRi and evaluated specificity and sensitivity of two methods to detect S100B for identification of earlyonset severe preeclampsia and PBI.

\section{MATERIALS AND METHODS}

\section{Study design and ethical approval}

This retrospective study protocol was approved by the Ethics Committee of the Maternal and Child Health Hospital of Hunan Province (No. 2013-P2-006-01) and complied with the Declaration of Helsinki. Informed consents were obtained from all participants.

\section{Patients}

Between January 2017 and December 2018, nine pregnant women with early-onset severe preeclampsia, showing fetal distress and causing hypoxic-ischemic encephalopathy (HIE) after delivery, and 13 pregnant women without early-onset severe preeclampsia and having prenatal diagnosis when they were 32-34 weeks pregnant at the Maternal and Child Health Hospital of Hunan Province, were assessed for eligibility based on inclusion and exclusion criteria. Their nationality, age, parity, fetal number, weeks pregnant, inflammation status, tumor status, and family history of hypertension were recorded.

Inclusion criteria: 1. they were diagnosed fetal distress by non-stress test and ultrasound and caused hypoxic-ischemic encephalopathy after delivery; 2. Han nationality; 3. 35 years old; 4. Primiparous; 5. Singleton pregnancies; 6; 32-34 weeks pregnant; 7. No inflammation; 8. No tumors, and 9. No family history of hypertension. Pregnant women included in the control group: 1. Perinatal and they delivered baby in full-term smoothly; 2. Han people; 3.35 years old; 4. Primiparity; 5. Singleton pregnancy; 6. 32-34 weeks pregnant; 7. No inflammation; 8. No tumors and 9 . No family history of hypertension.

\section{Sample collection}


In the control group, we obtained $3 \mathrm{~mL}$ of blood from the pregnant women's antecubital veins at 8:00 a.m. and $5 \mathrm{~mL}$ amniotic fluid from the amniotic sac of the uterus at 4:00 p.m. In the study group, in addition to the peripheral veins and amniotic fluid, we also collected $3 \mathrm{~mL}$ of blood from the umbilical vein in the operating room in cases of fetuses with diagnosed fetal distress in utero by non-stress test (NST) and ultrasound. All samples were centrifuged at 3,500 $\mathrm{rpm}$ at $4^{\circ} \mathrm{C}$ for $15 \mathrm{~min}$. Supernatants were deposited at $-80^{\circ} \mathrm{C}$. The $\mathrm{S} 100 \mathrm{~B}$ protein expression was detected using enzyme-linked immunosorbent assay (ELISA) and surface plasmon resonance imaging (SPRi) in the hospital laboratory according to the instruction manual $[17,18]$.

\section{Statistical analysis}

The data were analyzed with Statistical Product and Service Solutions (SPSS) version 25.0 software (IBM, Chicago, IL, USA). S100B concentrations were presented as the mean \pm standard deviation (SD), and compared by Wilcoxcon rank sum test. The correlation of S100B levels among maternal blood, cord blood, and amniotic fluid in the study and control groups were evaluated using Spearman's correlation test. Receiver operating characteristic (ROC) curve analysis was assessed for early-onset severe preeclampsia and PBI diagnostic values of the ELISA and the SPRi in maternal blood, cord blood and amniotic fluid. $\mathrm{P}<0.05$ was considered a statistical significance.

\section{RESULTS}

\section{Characteristics of study participants}

The baseline characteristics of maternal and fetus status in the control and study groups were listed in Table 1. It was suggested that there were no significances in pregnant week and body mass index (BMI) for pregnant women in both groups. Blood pressure was 160-190/100$120 \mathrm{mmHg}$ in the study group and lower than $140 / 90 \mathrm{mmHg}$ in the control group. $2+$ to $4+$ proteinuria was found in the study group, while - proteinuria was observed in the control group. Results of fetal status suggested that non-stress test was abnormal for the study group and normal for the control group. Ultrasound score was 4-6 for the study group and 8 for the control group. Fetus weight was normal in the control group while fetal growth was restricted in the study group. 


\section{Concentrations of S100B protein in the study and control groups}

As shown in Table 2, there were no statistical differences in the concentration of S100B protein in the amniotic fluid tested by ELISA between the study group and the control group ( $p$ > 0.05). Following SPRi measurement, a significant difference in the concentration of S100B protein in the amniotic fluid was found between two groups $(\mathrm{p}<0.05)$. Furthermore, there was a significant difference in the concentration of S100B protein in maternal blood between the study group and the control group tested by ELISA and SPRi methods (both $p<0.05$ ).

\section{Correlation of concentrations of S100B between maternal blood and amniotic fluid in the control and study groups}

As shown in Table 3, for the study group, the concentration of ELISA-S100B protein in maternal blood was positively correlated with the concentration of SPRi-S100B protein in maternal blood $(0.883, \mathrm{p}<0.05)$. The concentration of ELISA-S100B in amniotic fluid was positively correlated with the concentration of SPRi-S100B in amniotic fluid $(0.720, p<0.05)$. However, there were no positive correlations between ELISA-S100B protein in the maternal blood and ELISA-S100B and or SPRi-S100B in amniotic fluid, between SPRi-S100B in maternal blood and ELISA-S100B and or SPRi-S100B in amniotic fluid ( $p>0.05$ ).

\section{Correlation of ELISA-S100B and SPRi-S100B concentrations in study group}

For the study group, Table 4 showed that there was a positive correlation between ELISAS100B expression level and SPRi-S100B expression level in maternal blood $(0.850, \mathrm{p}<0.05)$ and ELISA-S100B in umbilical cord blood $(0.741, \mathrm{p}<0.05)$ between SPRi-S100B in maternal blood and ELISA-S100B in umbilical cord blood (0.706, p < 0.05), and or SPRi-S100B in umbilical cord blood $(0.620, \mathrm{p}<0.05)$ and in amniotic fluid $(0.579, \mathrm{p}<0.05)$. By contrast, there were no positive correlations between the ELISA-S100B in the maternal blood and ELISAS100B and or SPRi-S100B in the amniotic fluid and SPRi-S100B in the umbilical cord blood $(p>0.05)$. There were no positive correlations for ELISA-S100B in umbilical cord blood and ELISA-S100B and SPRi-S100B in the amniotic fluid, and the SPRi-S100B in the umbilical cord blood ( $p>0.05$ ). The ELISA-S100B expression level in amniotic fluid was not positively correlated with the SPRi-S100B in maternal blood, in umbilical cord blood and in amniotic fluid 
( $\mathrm{p}>0.05)$. There were no statistical differences in SPRi-S100B between the amniotic fluid and the umbilical cord blood ( $\mathrm{p}>0.05)$.

\section{ROC analysis for ELISA-S100B and SPRi-S100B}

Table 5 and Figure 1 showed ELISA-S100B and SPRi-S100B in maternal blood and in amniotic fluid. ROC analysis proved that the area under ROC curve (AUC) of SPRi-S100B in maternal blood was 0.959 ( $\mathrm{p}<0.001$ ), which was greater than that of ELISA-S100B in maternal blood of $0.846(\mathrm{p}=0.07)$. The AUC of SPRi-S100B in amniotic fluid was $0.858(\mathrm{p}=0.002)$, which was greater than that of ELISA-S100B in amniotic fluid of $0.709(\mathrm{p}=0.102)$. There were no statistical differences in the AUC for ELISA-S100B in amniotic fluid ( $p>0.05$ ). Additionally, the sensitivity and specificity of ELISA and SPRi were provided in Table 6. The cut-off level for detecting ELISA-S100B and SPRi-S100B in maternal blood was $178 \mathrm{ng} / \mathrm{mL}$ and $181 \mathrm{ng} / \mathrm{mL}$, the sensitivity was $66.7 \%$ and $100 \%$, and the specificity was $44.4 \%$ and $84.6 \%$, respectively. The cut-off level for detecting ELISA-S100B and SPRi-S100B in amniotic fluid was $126 \mathrm{ng} / \mathrm{mL}$ and $99 \mathrm{ng} / \mathrm{mL}$, the sensitivity was $0 \%$ and $100 \%$, and the specificity was $0 \%$ and $69.2 \%$, respectively. Above findings indicated that SPRi-S100B is superior to the ELISA-S100B for the diagnosis of early-onset severe preeclampsia in pregnant women.

\section{DISCUSSION}

In pregnant women with early-onset and severe preeclampsia, arteriolar convulsions can cause fetal distress through poor placental perfusion, which can lead to PBI and neonatal hypoxic ischemic encephalopathy. Despite these potential issues, screening high-risk fetuses for brain injury early and accurately remains challenging [2]. In this study, the concentrations of S100B protein in samples of pregnant women with and without preeclampsia were detected by ELISA and SPRi methods, and ithe feasibility, safety and accuracy of ELISA and SPRi were evaluated, providing the evidence that SPRi-S100B protein level can accurately and reliably provide clinical benefits to identify early-onset severe preeclampsia.

$\mathrm{S} 100 \mathrm{~B}$ is a calcium-binding protein concentrated in nervous glial cells, which is essential to oligodendrocyte (OL) differentiation and maturation. Elevated S100B is suggested to disrupt astrocyte proliferation and inflammation while destroy neuronal and synaptic integrity, reduce the morphological maturation of differentiated OL [11]. The high S100B levels in biological fluids 
are thus considered biomarkers of pathological conditions in many brain disorders [12]. Serum S100B levels can be used not only as a biomarker for hypoxic-ischemic encephalopathy, but also as a useful marker of perinatal acute brain injury, especially for fetal distress [2, 10, 21]. Also, it has been used to monitor brain damage and evaluate neuroprotective effects in high-risk newborns $[22,23]$. S100B concentration was also found to be associated with umbilical artery $\mathrm{pH}$, amplitude integral electroencephalogram (EEG), hypoxic ischemic encephalopathy (HIE) stage and death/sequelae up to age 6 [24]. S100B was positively correlated with the severity of the disease and the risk of neurodevelopmental sequelae and death [25]. The elevation of plasma S100B in patients with preeclampsia may be secondary to cerebral vascular injury, suggesting that the brain is involved in the occurrence of preeclampsia [26]. In addition, for preeclampsia, reactive oxygen species (ROS) are produced by oxidative stress, which can increase S100B levels in amnion [27]. In a previous study, the severe preeclampsia showed higher S100B levels than the mild preeclampsia or normotensive [28]. Levels of S100B remained higher in women who had experienced preeclampsia in one year postpartum than those with previous normal pregnancies [30]. S100B should be a potential biomarker of the central nervous system (CNS), as well as in perinatal development and damage [31]. S100B is also applied to monitor the effect of maternal prenatal treatment, such as the administration of NO and glucocorticoids [32]. In this study, compared to the control, increased expression levels of S100B protein in maternal blood and amniotic fluid of pregnant women with early-onset severe preeclampsia were found. Previous studies reported that ELISA can be used to detect changes in S100B concentration in serum and cerebrospinal fluid (CSF) with high sensitivity and specificity, and it should be a simple diagnosis tool for preeclampsia [32, 33]. SPRi is a label-free, real-time method to monitor and diagnose fetal diseases $[34,35]$. This study indicated that there are significant differences in concentrations of S100B in maternal blood between the two groups assayed by ELISA and SPRi. Previous studies showed that high S100B protein levels indicate development of PBI [24]. Additionally, the Youden index of SPRi-S100B in pregnant women's blood and amniotic fluid were higher than the control, indicating a greater diagnostic value. Based on these results, it was believed that the SPRi-S100B used as an indicator of early-onset severe preeclampsia is better than that of ELISA-S100B. Overall, our experiments provide real-time, non-invasive, and relative quantitative estimates of early-onset severe preeclampsia, as well as preliminary evidence for monitoring, diagnosing, and predicting early-onset severe preeclampsia. 


\section{Limitations}

This is a study with fewer cases from a single center, so results may not accurately represent populations in different geographic areas. Future studies will require more patients and careful matching of key clinical indicators to ultimately quantify the potential clinical value of PBI and early onset of severe preeclampsia using the SPRi-S100B.

\section{CONCLUSIONS}

Increased levels of S100B are found in maternal blood and amniotic fluid of pregnant women with early-onset severe preeclampsia compared to healthy pregnant women. There was a positive correlation in S100B concentration between maternal blood and amniotic fluid. SPRiS100B is sensitive to ELISA-S100B for the diagnosis of early onset of severe preeclampsia and PBI.

\section{Acknowledgements}

The authors would like to thank Pro. Ren-He, Yu from Central South University for statistical analysis. We would also like to thank Dr. Zhi-You, Wang from Changsha University for performing the experiments.

\section{Conflict of interest}

The authors declare that they have no competing interests.

\section{Funding}

This work was supported by the Department of Science \& Technology, Hunan Province, China (No.2013FJ3112 and No.2018JJ6098).

\section{REFERENCES}

1. Nirupama R, Divyashree S, Janhavi P, et al. Preeclampsia: Pathophysiology and management. J Gynecol Obstet Hum Reprod. 2021; 50(2): 101975, doi: 10.1016/j.jogoh.2020.101975, indexed in Pubmed: $\underline{33171282}$. 
2. Rana S, Lemoine E, Granger JP, et al. Preeclampsia: Pathophysiology, Challenges, and Perspectives. Circ Res. 2019; 124(7): 1094-1112, doi:

10.1161/CIRCRESAHA.118.313276, indexed in Pubmed: $\underline{30920918 .}$

3. Méhats C, Miralles F, Vaiman D. [New perspectives on preeclampsia]. Med Sci (Paris). 2017; 33(12): 1079-1088, doi: 10.1051/medsci/20173312015, indexed in Pubmed: $\underline{29261496 .}$.

4. Hagberg B, Hagberg G, Beckung E, et al. Changing panorama of cerebral palsy in Sweden. VIII. Prevalence and origin in the birth year period 1991-94. Acta Paediatr. 2001; 90(3): 271-277, indexed in Pubmed: 11332166.

5. Pierrat V, Haouari N, Liska A, et al. Groupe d'Etudes en Epidémiologie Périnatale. Prevalence, causes, and outcome at 2 years of age of newborn encephalopathy: population based study. Arch Dis Child Fetal Neonatal Ed. 2005; 90(3): F257-F261, doi: 10.1136/adc.2003.047985, indexed in Pubmed: 15846019.

6. Bergman L, Akhter T, Wikström AK, et al. Plasma levels of S100B in preeclampsia and association with possible central nervous system effects. Am J Hypertens. 2014; 27(8): 1105-1111, doi: 10.1093/ajh/hpu020, indexed in Pubmed: 24610883.

7. Donato R. S100: a multigenic family of calcium-modulated proteins of the EF-hand type with intracellular and extracellular functional roles. Int J Biochem Cell Biol. 2001; 33(7): 637-668.

8. Prez KD, Fan L. Structural Basis for S100B Interaction with its Target Proteins. J Mol Genet Med. 2018; 12(3), doi: 10.4172/1747-0862.1000366, indexed in Pubmed: $\underline{30854023 .}$.

9. Anastasi E, Gennarini G, Del Mo, et al. Performance assessment of a fully automated electro-chemiluminescence immunoassay systemfor serum S100B protein. J Biol Regul Homeost Agents. 2018; 32(4): 1039-1043.

10. Thelin EP, Nelson DW, Bellander BMA. review of the clinical utility of serum S100B protein levels in the assessment of traumatic braininjury. Acta Neurochir (Wien). 2017; 159(2): 209-225.

11. Santos G, Barateiro A, Gomes CM, et al. Impaired oligodendrogenesis and myelination by elevated S100B levels during neurodevelopment. Neuropharmacology. 2018; 129: 6983, doi: 10.1016/j.neuropharm.2017.11.002, indexed in Pubmed: 29126910. 
12. Sen J, Belli A. S100B in neuropathologic states: the CRP of the brain? J Neurosci Res. 2007; 85(7): 1373-1380, doi: 10.1002/jnr.21211, indexed in Pubmed: 17348038.

13. Gazzolo D, Pluchinotta F, Lapergola G, et al. The Ca-Binding S100B Protein: An Important Diagnostic and Prognostic Neurobiomarker in Pediatric Laboratory Medicine. Methods Mol Biol. 2019; 1929: 701-728, doi: 10.1007/978-1-4939-9030-6_44, indexed in Pubmed: $\underline{30710306 .}$

14. Cai Rm, Weng Zp, Wang Yy, et al. [Relationship of S100B protein expression and the pathogenesis of early-onset and late-onset preeclampsia]. Zhonghua Fu Chan Ke Za Zhi. 2012; 47(7): 510-513, indexed in Pubmed: 23141161.

15. Astrand R, Undén J. Clinical Use of the Calcium-Binding S100B Protein, a Biomarker for Head Injury. Methods Mol Biol. 2019; 1929: 679-690, doi: 10.1007/978-1-4939-90306_42, indexed in Pubmed: 30710304.

16. Mir IN, Chalak LF. Serum biomarkers to evaluate the integrity of the neurovascular unit. Early Hum Dev. 2014; 90(10): 707-711, doi: 10.1016/j.earlhumdev.2014.06.010, indexed in Pubmed: 25064445.

17. Leite MC, Galland F, Brolese G, et al. A simple, sensitive and widely applicable ELISA for S100B: Methodological features of the measurement of this glial protein. J Neurosci Methods. 2008; 169(1): 93-99, doi: 10.1016/j.jneumeth.2007.11.021, indexed in Pubmed: $\underline{18178255 .}$

18. Vaisocherová H, Faca VM, Taylor AD, et al. Comparative study of SPR and ELISA methods based on analysis of CD166/ALCAM levels in cancer and control human sera. Biosens Bioelectron. 2009; 24(7): 2143-2148, doi: 10.1016/j.bios.2008.11.015, indexed in Pubmed: 19157844.

19. Campbell K, Huet AC, Charlier C, et al. Comparison of ELISA and SPR biosensor technology for the detection of paralytic shellfish poisoning toxins. J Chromatogr B Analyt Technol Biomed Life Sci. 2009; 877(32): 4079-4089, doi: $\underline{\text { 10.1016/j.jchromb.2009.10.023, indexed in Pubmed: } 19926541 .}$

20. Michetti F, Corvino V, Geloso MC, et al. The S100B protein in biological fluids: more than a lifelong biomarker of brain distress. J Neurochem. 2012; 120(5): 644-659, doi: 10.1111/j.1471-4159.2011.07612.x, indexed in Pubmed: 22145907. 
21. Murabayashi M, Minato M, Okuhata Y, et al. Kinetics of serum S100B in newborns with intracranial lesions. Pediatr Int. 2008; 50(1): 17-22, doi: 10.1111/j.1442200X.2007.02506.x, indexed in Pubmed: 18279199.

22. Lv H, Wang Q, Wu S, et al. Neonatal hypoxic ischemic encephalopathy-related biomarkers in serum and cerebrospinal fluid. Clin Chim Acta. 2015; 450: 282-297, doi: 10.1016/j.cca.2015.08.021, indexed in Pubmed: 26320853.

23. Gazzolo D, Abella R, Marinoni E, et al. New markers of neonatal neurology. J Matern Fetal Neonatal Med. 2009; 22 Suppl 3: 57-61, doi: 10.1080/14767050903181468, indexed in Pubmed: 19718579.

24. Michetti F, Gazzolo D. S100B protein in biological fluids: a tool for perinatal medicine. Clin Chem. 2002; 48(12): 2097-2104, indexed in Pubmed: 12446464.

25. Zaigham M, Lundberg F, Olofsson P. Protein S100B in umbilical cord blood as a potential biomarker of hypoxic-ischemic encephalopathy in asphyxiated newborns. Early Hum Dev. 2017; 112: 48-53, doi: 10.1016/j.earlhumdev.2017.07.015, indexed in Pubmed: $\underline{28756088}$.

26. Wikström AK, Ekegren L, Karlsson M, et al. Plasma levels of S100B during pregnancy in women developing pre-eclampsia. Pregnancy Hypertens. 2012; 2(4): 398-402, doi: 10.1016/j.preghy.2012.03.001, indexed in Pubmed: 26105610.

27. Tskitishvili E, Komoto Y, Temma-Asano K, et al. S100B protein expression in the amnion and amniotic fluid in pregnancies complicated by pre-eclampsia. Mol Hum Reprod. 2006; 12(12): 755-761, doi: 10.1093/molehr/gal083, indexed in Pubmed: $\underline{17023485 .}$.

28. Vettorazzi J, Torres FV, de Ávila TT, et al. Serum S100B in pregnancy complicated by preeclampsia: A case-control study. Pregnancy Hypertens. 2012; 2(2): 101-105, doi: 10.1016/j.preghy.2011.11.004, indexed in Pubmed: 26105095.

29. Bergman L, Åkerud H, Wikström AK, et al. Cerebral Biomarkers in Women With Preeclampsia Are Still Elevated 1 Year Postpartum. Am J Hypertens. 2016; 29(12): 1374-1379, doi: 10.1093/ajh/hpw097, indexed in Pubmed: 27653032.

30. Artunc-Ulkumen B, Guvenc Y, Goker A, et al. Maternal Serum S100-B, PAPP-A and IL6 levels in severe preeclampsia. Arch Gynecol Obstet. 2015; 292(1): 97-102, doi: 10.1007/s00404-014-3610-0, indexed in Pubmed: 25573795. 
31. Michetti F, Gazzolo D. S100B protein in biological fluids: a tool for perinatal medicine. Clin Chem. 2002; 48(12): 2097-2104, indexed in Pubmed: 12446464.

32. Steiner J, Bogerts B, Schroeter ML, et al. S100B protein in neurodegenerative disorders. Clin Chem Lab Med. 2011; 49(3): 409-424, doi: 10.1515/CCLM.2011.083, indexed in Pubmed: 21303299.

33. Erickson JA, Grenache DG. Performance Evaluation of a Serum S-100B ELISA for Use with Cerebrospinal Fluid. J Appl Lab Med. 2018; 2(5): 811-813, doi: 10.1373/jalm.2017.024752, indexed in Pubmed: $\underline{3636871 .}$

34. Homola J. Surface plasmon resonance sensors for detection of chemical and biological species. Chem Rev. 2008; 108(2): 462-493, doi: 10.1021/cr068107d, indexed in Pubmed: $\underline{18229953 .}$.

35. Howe CL, Webb KF, Abayzeed SA, et al. Surface plasmon resonance imaging of excitable cells. J Phys D Appl Phys. 2019; 52(10): 104001, doi: 10.1088/13616463/aaf849, indexed in Pubmed: $\underline{30867618 .}$. 

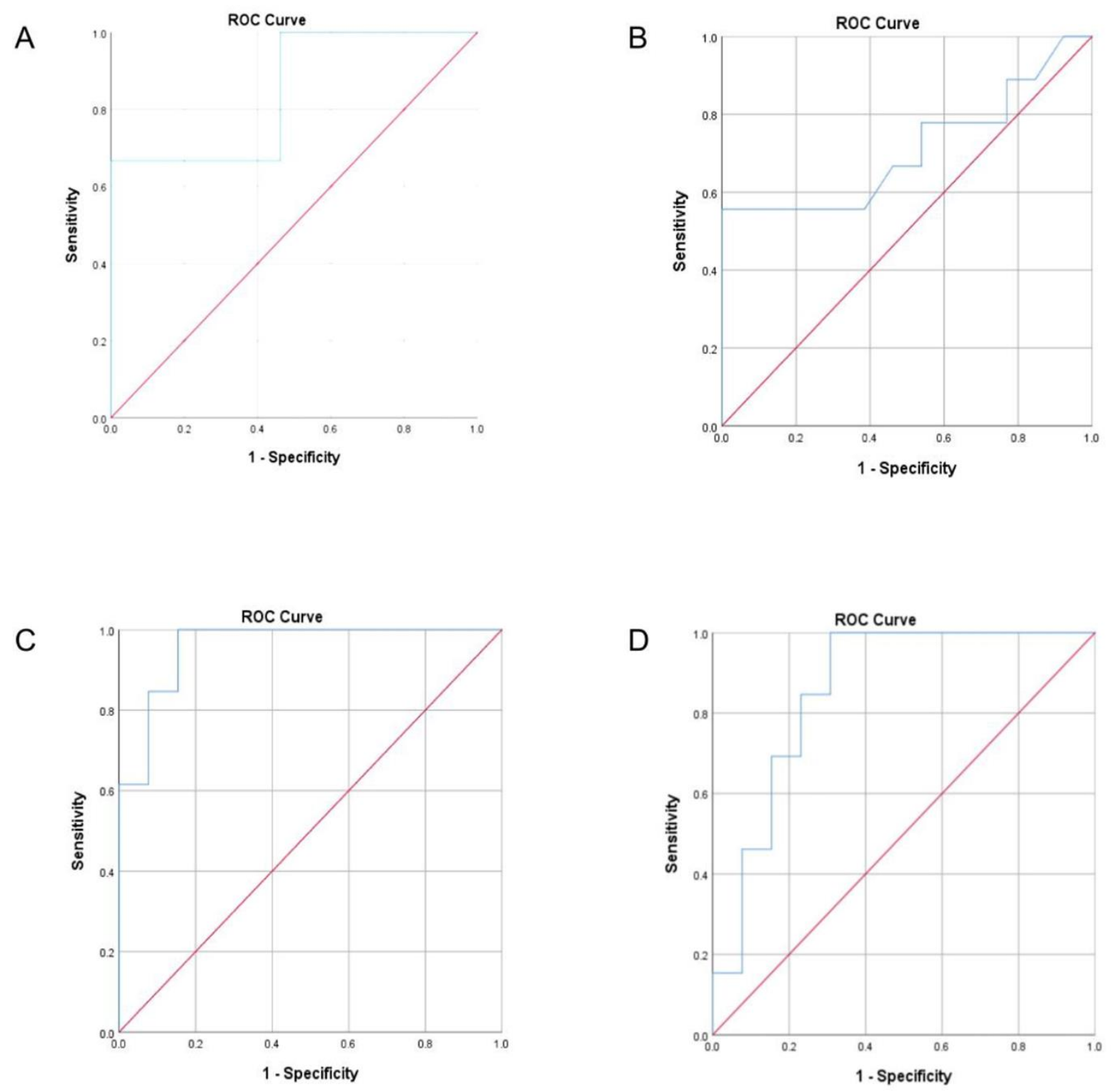

Figure 1. Receiver Operating Characteristic (ROC) curve of S100B protein in blood and amniotic fluid of pregnant women with preeclampsia detected by ELISA and SPRi; A. ROC of ELISA-S100B in maternal blood; B. ROC of ELISA-S100B in amniotic fluid; C. ROC of SPRiS100B in maternal blood; D. ROC of SPRi-S100B in amniotic fluid

Table 1. Baseline characteristics of maternal and fetus status in both study and control groups

\begin{tabular}{|l|l|l|}
\hline Items & Study group & Control group \\
\hline Maternal status & & \\
\hline
\end{tabular}




\begin{tabular}{|l|l|l|}
\hline Pregnant week & $32-34$ & $32-34$ \\
\hline BMI & $18-25$ & $18-25$ \\
\hline $\begin{array}{l}\text { Blood pressure } \\
{[\mathrm{mmHg}]}\end{array}$ & $160-190 / 100-120$ & $<140 / 90$ \\
\hline Proteinuria & ++ to ++++ & - \\
\hline Fetal status & & Normal \\
\hline Non-stress test & Abnormal & 8 \\
\hline Ultrasound scores & $4-6$ & Normal \\
\hline Weight & Fetal growth restriction & \\
\hline
\end{tabular}

BMI — body mass index

Table 2. Comparison of the ELISA-S100B and SPRi-S100B in study and control groups

\begin{tabular}{lllll}
\hline Variables & Control group $(\mathrm{n}=13)$ & Study group $(\mathrm{n}=9)$ & $\mathrm{Z}$ & $\mathrm{p}$ \\
\hline Maternal blood (ELISA-S100B) & $111.63 \pm 42.64$ & $198.91 \pm 51.02$ & 2.709 & 0.007 \\
Maternal blood (SPRi-S100B) & $115.18 \pm 51.02$ & $209.01 \pm 27.54$ & 3.976 & 0.000 \\
Amniotic fluid (ELISA-S100B) & $168.49 \pm 37.33$ & $144.93 \pm 42.74$ & 1.637 & 0.102 \\
Amniotic fluid (SPRi-S100B) & $82.88 \pm 45.12$ & $142.88 \pm 22.93$ & 3.103 & 0.002 \\
\hline
\end{tabular}

Table 3. Correlations of S100B protein concentrations in the control group between maternal blood and amniotic fluid

$\begin{array}{llll}\text { Maternal blood } & \text { Amniotic fluid } & \text { Maternal blood } & \text { Amniotic fluid } \\ (\text { ELISA-S100B }) & \text { (ELISA-S100B }) & (\text { SPRi-S100B }) & (\text { SPRi-S100B })\end{array}$

Maternal blood (ELISA- 1.000

S100B)

Amniotic fluid (ELISA- $\quad-0.055 \quad 1.000$

S100B) 
Maternal blood (SPRi-

$0.883^{* *}$

0.016

1.000

S100B)

Amniotic fluid (SPRi-

0.055

$0.720^{* *}$

0.121

1.000

S100B)

** indicated $\mathrm{p}<0.05$

Table 4. Correlations of S100B protein concentrations in the study group

\begin{tabular}{|c|c|c|c|c|c|c|}
\hline & $\begin{array}{l}\text { Maternal } \\
\text { blood } \\
\text { (ELISA- } \\
\text { S100B) }\end{array}$ & $\begin{array}{l}\text { Umbilical } \\
\text { cord blood } \\
\text { (ELISA- } \\
\text { S100B) }\end{array}$ & $\begin{array}{l}\text { Amniotic fluid } \\
\text { (ELISA- } \\
\text { S100B) }\end{array}$ & $\begin{array}{l}\text { Maternal } \\
\text { blood } \\
\text { (SPRi- } \\
\text { S100B) }\end{array}$ & $\begin{array}{l}\text { Umbilical } \\
\text { cord blood } \\
\text { (SPRi- } \\
\text { S100B) }\end{array}$ & $\begin{array}{l}\text { Amniotic } \\
\text { fluid } \\
\text { (SPRi- } \\
\text { S100B) }\end{array}$ \\
\hline $\begin{array}{l}\text { Maternal blood (ELISA- } \\
\text { S100B) }\end{array}$ & 1.000 & & & & & \\
\hline $\begin{array}{l}\text { Umbilical cord blood } \\
\text { (ELISA-S100B) }\end{array}$ & $0.741^{*}$ & 1.000 & & & & \\
\hline $\begin{array}{l}\text { Amniotic fluid (ELISA- } \\
\text { S100B) }\end{array}$ & 0.213 & 0.650 & 1.000 & & & \\
\hline $\begin{array}{l}\text { Maternal blood (SPRi- } \\
\text { S100B) }\end{array}$ & $0.850^{* *}$ & $0.706^{*}$ & 0.176 & 1.000 & & \\
\hline $\begin{array}{l}\text { Umbilical cord blood (SPRi- } \\
\text { S100B) }\end{array}$ & 0.562 & 0.517 & 0.233 & $0.620 *$ & 1.000 & \\
\hline Amniotic fluid (SPRi-S100B) & 0.443 & 0.333 & 0.533 & $0.579 *$ & 0.313 & 1.000 \\
\hline
\end{tabular}

indicated $\mathrm{p}<0.05 ;{ }^{* *}$ indicated $\mathrm{p}<0.01$.

Table 5. Receiver Operating Characteristic analysis of the S100B protein concentration

\begin{tabular}{llll}
\hline & AUC & $\mathrm{p}$ & $95 \%$ CI \\
\hline Maternal blood (ELISA-S100B) & 0.846 & 0.007 & $0.672-1.000$ \\
Maternal blood (SPRi-S100B) & 0.959 & 0.000 & $0.888-1.000$ \\
Amniotic fluid (ELISA-S100B) & 0.709 & 0.102 & $0.463-0.956$ \\
Amniotic fluid (SPRi-S100B) & 0.858 & 0.002 & $0.705-1.000$ \\
\hline
\end{tabular}

AUC - the area under ROC curve; $\mathrm{CI}$ - confidence interval 
Table 6. Clinical significance of S100B protein detected by SPRi and ELISA in maternal blood and amniotic fluid

\begin{tabular}{|c|c|c|c|}
\hline & Sensitivity & Specificity & Youden Index \\
\hline $\begin{array}{l}\text { Maternal blood (ELISA- } \\
\text { S100B) }\end{array}$ & 0.667 & 1.000 & 0.667 \\
\hline $\begin{array}{l}\text { Maternal blood (SPRi- } \\
\text { S100B) }\end{array}$ & 1.000 & 0.846 & 0.846 \\
\hline $\begin{array}{l}\text { Amniotic fluid (ELISA- } \\
\text { S100B) }\end{array}$ & 0.444 & 0.000 & -0.556 \\
\hline $\begin{array}{l}\text { Amniotic fluid (SPRi- } \\
\text { S100B) }\end{array}$ & 1.000 & 0.692 & 0.692 \\
\hline
\end{tabular}

